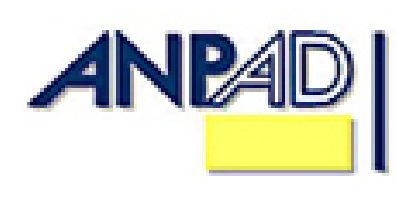

Available online at http://www.anpad.org.br/bar

BAR, Rio de Janeiro, v. 11, n. 2, art. 2, pp. 145-163, Apr./June 2014

$(\mathrm{cc})$ EY-

\title{
Life, Work and Sustainable Learning Practices: A Study on a Small Business Network
}

\author{
Ana Silvia Rocha Ipiranga \\ E-mail address: ana.silvia@pq.cnpq.br \\ Universidade Estadual do Ceará - UECE \\ Av. Paranjana, 1700, Campus Itapery, 60740-000, Fortaleza, CE, Brazil. \\ Marisia Monte Silva Aguiar \\ E-mail address: marisiamonte@gmail.com \\ Universidade Estadual do Ceará - UECE \\ Av. Paranjana, 1700, Campus Itapery, 60740-000, Fortaleza, CE, Brazil.
}

Received 22 September 2012; received in revised form $1^{\text {st }}$ November 2013 (this paper has been with the authors for two revisions); accepted 17 December 2013; published online $1^{\text {st }}$ April 2014. 


\begin{abstract}
Knowledge and knowing processes as work and life practices are not univocal. They are not related to knowledge as an autonomous body of propositions, but permeated with new identities and action modes, which are continuously formed, promoting learning opportunities. The objective of this research is formulated in the understanding of this shift between knowing and knowledge when describing practical learning in everyday work life, reflecting on the implications of this social labor process on small business network sustainability. A qualitative case study approach was used. In line with the theoretical and epistemological choices that guided this research, we decided to use an analysis of discursive practices approach and, accordingly, data collection was based on triangulation techniques in favor of interpretation enrichment. The knowledge to act, revealed in the analysis, suggested that organizations are social worlds forming a standard that holds life, work and organizational practices together. They negotiate, circulate, transform and reproduce, forming a network of actors and favoring sustainable practices learning.
\end{abstract}

Key words: learning practices; network; small enterprises. 


\section{Introduction}

Small businesses, given their magnitude nationally, play a relevant role in the construction of Brazil's development. However, there are too many difficulties faced by this organizational contingent to insist on acting alone. They face new contemporary grouping tendencies in a cooperative and competitive pari passu manner around common goals, with an objective towards their enterprises' sustainability.

Cooperation and competition are experienced through actors' participation. Negotiation of common objectives between small businesses stimulates learning as the motivating factor behind the alternating forces of cooperation and competition in the organizational context of work life. To the extent that these practices are socialized between small businesses' actors, making them common in some cases, one perceives the emergence of a sustainability that leads a collective enterprise to stand out in the market.

These discussions highlight the perspective of organizational learning (OL) as a social phenomenon, emphasizing action as situated in a historical and cultural context. This characterizes the learning approach based on practices that occur in the workplace (Elkjaer \& Wahlgren, 2005; Schatzki, 2001). This perspective emphasizes that learning emerges from a context of interactions (knowing), through different forms of participation, in a way that this knowledge is being continuously negotiated and reproduced in everyday work life (Nicolini, Gherardi, \& Yanow, 2003).

Reckwitz (2002) has investigated the idea of knowledge based on the notion of tension going beyond dichotomies, treating knowing/knowledge as an inseparable dynamic. From the perspective, knowing precedes knowledge in both the logical and chronological aspects, since knowledge is considered an institutionalized interpretation of knowing, and is in essence is a precondition for learning to occur (Gherardi, 2001, 2006).

Antonacopoulou, Jarvis, Andersen, Elkjaer and Hoyrup (2005) deepened these discussions by proposing the question of how we can improve organizational sustainability through learning that occurs in the workplace as concomitant learning forms of working and living. The authors take into account current thinking about learning that occurs continuously throughout life, directing the discussion of workplace learning as a key element of learning that happens during life's journey. This perspective illuminates a new learning nuance of working and living in the complexity of organizational context.

The theoretical links between dimensions of learning practice that are situated in the interconnections between knowing, life and work journeys show the relevance of this research. They indicate a gap in literature not widely explored until now in understanding the meaning of a network of entrepreneurs' actions in the furniture sector, while sustainable learning practices are negotiated, circulated and reproduced in the day-to-day work life.

In order to engender discussion on these analytical perspectives, this study has the objective to describe the learning practices that occur in day-to-day work life, reflecting on the implications of this social process on small-business network sustainability. This study is guided by the following questions: What are learning practices and how do they occur in everyday work life? What are the implications of this learning for sustainability of the small business network under study?

The field of study chosen was the Association of Small Cabinet Maker Businesses of Fortaleza (AMFOR) due to its local recognition in the development of sustainable practices. The research in question is exploratory and descriptive, using a qualitative case study approach (Bauer \& Gaskell, 2002). Data collection was done using semi-structured interviews with open-ended questions, formulated from theoretical-based critical reading as well as notes taken during the participation by the researcher in three meetings held at AMFOR. Based on the idea of an interview as a relational situation (Spink, 1999), this concept was applied to nine entrepreneurs that have participated in 
AMFOR since its founding. AMFOR's institutional documents were also compiled and analyzed, and asymmetrical observations were carried out. This allowed triangulation of collection techniques for the enrichment of interpretation. For this analysis and consistent with the theoretical and epistemological bases chosen to guide this study, the application of discursive practice procedures (Spink, 1999) was selected.

Seeking to systematize the obtained results, this paper was divided into six sections, the first of which is this introduction. In the second and the third sections, the theoretical bases guiding this research are presented. The fourth, fifth and sixth sections, respectively, lay out the methodology used to achieve the proposed objective, analysis and discussions, and, finally, the final considerations with study implications.

\section{Learning Based on Practices and Work Experience as Learning}

Research on learning in organizations as a topic dates back to the 1950s and reached its height in the late 1980s. Since the early 1990s, starting from research developed by Lave and Wenger (1991), Brown and Duguid (1991), Cook and Yanow (1993), there has been an area within Organizational Learning, which discusses forms of conceiving knowledge while having the competence to act. Studies published up to now have distanced themselves from the cognitivist group of studies, based on approaching the concept of knowledge guided by an epistemology of practice.

Schatzki (2002) illuminates the discussion of a site ontology or ontology of the social practices in which the social site is composed of a mesh (network) not only nexus of practices, but also materials arregements. The author emphasizes that it is the social site, where people coexist, is not a particular practice and / or a specific arrangement, but the interwoven mesh of different practices and arrangements that are interconnected and are articulated through to different human activities. It is this network that is what the author considers the order that organizes social life - it is the locus where social entities act, relate, position themselves in relation to each other and gain meaning and identity (Schatzki, 2002).

In this context, several authors have developed studies based on the concept of practice to understand different elements of everyday organizations. Between these studies is related to the theme of learning that have been analyzed from the point of view of practice (Gherardi, 2000; Nicolini et al., 2003). These studies characterized learning as a social phenomenon that is procedural, historical, culturally situated and mediated by artifacts and different forms of interaction (Easterby-Smith, Crossan, \& Nicolini, 2000; Nicolini et al., 2003; Nicolini \& Meznar, 1995).

These studies put into discussion that organizations are areas of practice. For example, Gherardi, (2006); Reckwitz (2002); Schatzki (2001, 2006) and Warde (2005), showed evidence that a theoretical, cohesive uniform body that can be called theory of practice does not exist; however certain characteristics indicate theories referring to practice.

In social theory, the perspective of the practice advocated by the Schatzki (2006) proposes a social ontology that does not privilege individuals, interactions, language, institutions and or structures as basic social phenomena. The social order, or human coexistence is conceived as something that unfolds in and from the meshes practices and or arrangements.

Based on the epistemology of practice different dichotomies are rejected, for example: mind/body, subject/object, structure/agency, objectivism/subjectivism, scientific knowledge/common sense (Schatzki, 2001). In addition, according to Hardt (1996), own denial of different dichotomies paves the way for creation and for practice. Schatzki (2001) points out that, in contemplating practices, researchers focused on activities, which enables the language being envisioned as discursive activity and not as structure, system or speech, while science is seen as an activity and not as a representation. According to Whittington (2006), these approaches direct their focus on the activities that happen in 
organizations' everyday lives as well as on the different processes that involve the action and production of people within the organization.

Schatzki (2006) also stressed that an organization, like any social phenomenon, is characterized as a set of practices consisting of arrangements of people, materials and artifacts. Furthermore, an organization consists of successive events that occur in a space-time context, and is the culmination of its constituents' actions.

Hence, from Schatzki (2001) and Reckwitz (2002), it can be noted that the theories that focus on practices are those which observe practices as a generic primary social unit, or as characterized by the creation of localized social practices, which is the smallest unit of social analysis.

Consistent with these discussions, Antonacopoulou (2008) claims that the authors who structure their approaches based on practice have searched for a definition for this term. The debate that involves the organizational-based learning practice approach has essentially been propagated from research developed by Silvia Gherardi. She refers to different theoretical approaches that hold learning and organizing ideas separately from practice (Gherardi, 2000, 2001, 2008, 2009).

For Gherardi (2006), the practice concept is represented by a web of connections in action; a connectivity linking these actions while they spread and multiply. The practices are recognized as a means for evaluation, and yet they are altered intensively from the scenario in which are represented, are still recognizable from the set of activities performed. In this sense, the practices, although reproducing and spreading continuously, are incomplete and indeterminate until they are executed so situated.

Accordingly, Nicolini, Gherardi and Yanow (2003) identified four approaches in their studies: one related to the phenomena of knowing and organizing apart from an aspect based on practice; the interpretive-cultural, referring to practice communities; the historical and cultural activity theory; and, finally, the translation sociology or actor-network theory.

After a few years, Gherardi (2000) employed another indication for the same set of approaches: theorizations about practice-based learning and knowing in organizations, arguing that what unites these theories are not ontological or epistemological presuppositions, but the centrality in the idea of practice and the fact they create knowledge from something practical and not as a result of decontextualized abstractions.

Starting in 2001, Gherardi and Nicolini have developed studies directed at OL based on two concepts used in sociology: participation in practice and reflexivity, suggesting the idea of substituting organizational learning for the learning-in-organizing concept. In this concept, learning may be understood as competent participation in a practice, a transformation form or perpetuation of knowledge, social production and reproduction. This practical approach is considered to be a set of activities in which knowledge is not separated from its making, emphasizing situations in which the activities coproduce knowledge through their very activity. Therefore, the practice becomes a topos that binds knowledge together with the making of it (Gherardi, 2008).

Works developed by Gherardi (2001, 2006, 2008, 2009) have investigated the idea of knowledge proposed by Reckwitz (2002). This author builds the notion of tension going beyond dichotomies from a holistic view, treating knowing/knowledge as an inseparable dynamic. From the perspective proposed by Nicolini et al. (2003), knowing precedes knowledge in both the logical and chronological aspects, since knowledge is considered an institutionalized interpretation of knowing. Knowing consists of constantly evolving activities and processes which perpetuate over time and coincide with collectively constructed ways of knowing and acting, all of which are relational and mediated by artifacts. Thus, it is possible to consider knowing to be a sociocultural phenomenon, which enables the exploration of less intentional, less instrumental, and more reflective knowledge facets, and is in essence is a precondition for learning to occur (Gherardi, 2006). 
In this context and as evidenced by Easterby-Smith, Crossan, and Nicolini (2000), groups of people from different organizations and cultural backgrounds are, for a period of time, aiming to analyze a problem or develop a project, therefore shaping a discursive community. According to the authors, this generates a situated discursive identity, allowing participants to compare different perspectives and realize what is remaining, not communicated, isolated and eventually what speech conflicts.

This situation is based on participants' positioning and on the discursive identities claim that allows for the displacement and crossing of boundaries between different communities. This promotes learning how to negotiate current relationships and negotiate changes in these relationships and develops a competence to act (Easterby-Smith et al., 2000; Nicolini et al., 2003).

Aiming to overcome the challenges encountered during the workday, according to Antonacopoulou et al. (2005), the debate about new forms to promote the learning structure under question is how we can improve an organization's sustainability; while at the same time making learning the driving force behind the expansion of engaging people. In these terms and according to the current approach of the importance of continuous learning that happens over the course of a lifetime, the authors emphasize that it is essential to focus discussion of workplace learning as a learning journey that is occurs throughout life.

According to the authors, learning from this perspective is not institutionalized in formal educational contexts or organized by external agents in terms of efficiency, but in complex organizations and conducted through the logics that prevail there. In this sense, learning is a part of human existence that develops in a social context of professional and organizational life. Skills development can be part of this learning, but the most important aspects are the construction of meanings and an image of the world; i.e. the construction of identities, collective practices and new life perspectives that this process creates. Learning as a way of life involves processes of exploration, questioning, the re-framing and transformations of situations in an organizations' work and life, being, therefore, innovative and creative forms of life learning (Antonacopoulou, Jarvis, Andersen, Elkjaer, \& Hoyrup, 2005).

\section{Sustainability and Sustainability Mobilization}

The discussion on sustainability appears to be a motivation for excellence in one of the most significant social mobilizations since the beginning of this century and millennium. There are numerous volunteer activities related to sustainability and its development. Companies in finance, hospitality and industrial sectors support them. Some of the most prominent entrepreneurs in these sectors are involved. This resulted in the creation, by large companies, of organizations committed to this movement, such as the World Business Council for Sustainable Development (WBCSD) and Caux Round Table (Barbieri, Vasconcelos, Andreassi, \& Vasconcelos, 2010).

The authors also point out that, from this movement's rise, a variety of principle charters and action guidelines have been prepared and are being supported by thousands of companies. Some examples include the Rotterdam Charter, Millennium Development Goals and Global Compact, among others. However, no social movement gathered more heads of state than the events in Rio de Janeiro in 1992 and Johannesburg in 2007 (Barbieri et al., 2010).

The speed with which this mobilization was accepted by various business segments, at least at the theoretical level, is unprecedented in the recent historical context of companies, with the publishing in 1987 of the initial landmark report of the World Commission on Environment and Development (WCED), known as the Brundtland Commission (Barbieri, 2007).

Initially, companies join the cause which advocates sustainability and its development from outside to inside, or in other words, as a way to respond to criticism and opposition to their 
performance when targeted by numerous government institutions and civil society organizations considering them responsible for environmental destruction with global social consequences. Only recently, companies began to join this project due to factors related to business needs - being a member of this movement has become a competitive factor, a differentiator for companies to remain in the market (Barbieri, 2007).

Ribeiro (2001) adds that, despite an unquestionable need for nature conservation on the part of the business, actions in this sense have greater repercussions only when developed by different social actors involving governments and markets. The author affirms that if there were no pressures from society and government, companies would not get involved in environmental issues.

Brazilian companies only began to invest in environmental and social programs protection in the early 1990's aimed at meeting the demands to show increasing environmental engagement. Hence, society and markets have increasingly recognized these companies for their actions.

Increasingly, organizations understand that the financial cost of reducing environmental liability and managing social conflicts may be higher than the cost of promoting responsible actions. Such actions have the power to influence public opinion in relation to the organization, guarantee investors' and consumers' confidence, and be reflected in organizational competitiveness (Vinha, 2003).

However, there are still companies looking to implement only symbolic reforms, responding, for example, only to environmental legislation. Companies that have greater credibility in the market have sought to develop comprehensive environmental management programs. These include ISO 9000 and ISO 14000 certificates, pursued in order to add value to products and to become a socially responsible organization (Vinha, 2003).

To be recognized as a socially responsible company, it is necessary for the organization to develop a constant dialogue with various actors and their stakeholders (employees, suppliers, customers, community, etc.) showing accountability to society, but also, to go beyond expectations related to legal requirements and international standards (Vinha, 2003). Therefore, the challenge for companies that practice sustainability is based on producing new forms of cooperation involving different actors and stakeholders, including competitors.

According to Ribeiro (2001), a company is considered sustainable when it has the ability to provide long-term value for its shareholders or owners, while also contributing to the resolution of environmental and social problems.

A fundamental perspective to consider when joining a social mobilization is the necessity to replace the old ways and practices for others that interpret current principles, objectives and recent movement directions. From the moment the organization is committed to a proposal linked with sustainability it becomes imperative to change its actions in pursuit of reducing adverse environmental and social impacts. This requires the use of new practices that can contribute to achieving sustainability (Barbieri et al., 2010).

\section{Methodology}

This study uses qualitative case study as a research method (Bauer \& Gaskell, 2002). As a study context, the Association of Small Cabinet Maker Businesses of Fortaleza (AMFOR) was chosen because it joins twelve entrepreneurs in a network of twelve small companies that manufacture custom designed furniture and thus it actively participates in the furniture sector in Ceará - Brazil. Another relevant point for the choice of AMFOR was its local recognition in the development of sustainable practices. Founded in 2006, it currently competes and cooperates with other industrial centers of the sector, for example, the City of Marco, which is also in Ceará. 
Considering a temporal cut since the creation of AMFOR in 2006, data collection was done using semi-structured interviews with open-ended questions, formulated from theoretical-based critical reading, as well as notes taken during the participation by the researcher in three meetings held at AMFOR. Of the total twelve entrepreneurs, nine participated in this research which are members of AMFOR since its founding, as described below in Table 1:

Table 1

\section{AMFOR Organizations Participants}

1.Organization: Dimensão Componentes Ltda. Foundation year - 2000

Entrepreneur: Male. Studies: complete medium. Total employees: 12

2.Organization: J.N. Marcenaria Ltda. Foundation year - 2000

Entrepreneur: Male. Studies: complete medium. Total employees: 10

3.Organization: Móveis Rebouças Ltda. Foundation year - 2000

Entrepreneur: Male. Studies: complete medium. Total employees: 30

4. Organization: Carvalho Móveis Ltda. Foundation year - 2001.

Entrepreneur: Male. Studies: complete medium. Total employees: 10

5.Organization: E. M. Móveis Ltda. Foundation year - 2002

Entrepreneur: Male. Studies: complete medium. Total employees: 10

6.Organization: C. A. Marcenaria Ltda. Foundation year - 2000

Entrepreneur: Male. Studies: complete medium. Total employees: 7

7.Organization: M. M. Móveis Projetados Ltda. Foundation year - 2002

Entrepreneur: Male. Studies: complete medium. Total employees: 12

8.Organization: M. N. L. Móveis Ltda. Foundation year - 2000

Entrepreneur: Male. Studies: complete medium. Total employees: 10

9.Organization: A. M. Fábrica de Sonhos Ltda. Foundation year - 2000

Entrepreneur: Male. Studies: complete medium. Total employees: 13

Note. Source: empirical research.

Given the objective of this study, which is identify and describe practices opted for the use of relational interview. This interview type, according to Spink (1999) is understood as the result of interaction between active subjects, including the researcher. In this sense, the semi-structured interview script helped guide a group conversation based on issues that emerged during the entrepreneur's explanation of their work practices. AMFOR's institutional documents were compiled and analyzed and unsystematic observations were carried out, allowing for the triangulation of data collection techniques for the enrichment of interpretation (Spink, 1999).

As previously discussed and ccording to Schatzki (2001) and Easterby-Smith et al. (2000), researchers contemplating learning practices focus on activities, which enables language to be envisioned as a discursive activity and AMFOR as a discursive community. On the basis of this theoretical and epistemological principle, analysis followed the discursive practices approach (Spink, 1999). This approach problematizes the discursive context, focusing analysis on the time of interaction, since knowledge is not in people's minds as something they do together. In this sense, the descriptions and explanations of the world are apparent in artifacts and social action forms, being interwoven by human activities (Gergen, 1985; Spink, 1999).

Considered a milestone, the creation processes of the AMFOR network in 2006 were delimited for context analysis according to a temporal perspective. After that, a search was conducted to identify the interpretative repertoires, as well as the discursive practices construction unit. The interpretative 
repertoires incorporate the subjects' positions in interaction, and these are placed in a constant negotiation process delineating this interpersonal space (Spink, 1999).

From the description of subjects' positions in interaction was carried out a mapping Network AMFOR from the application of software UCINET 6,357 and NetDraw 2,814. For the mapping of relationships between participants of the Network AMFOR, we chose to analyze the indices of the density and centrality (Alejandro \& Norman, 2005).

Table 2

Indices of Network Analysis

\begin{tabular}{ll}
\hline Indices & Concept \\
\hline Centrality & $\begin{array}{l}\text { Refers to the total number of participants to which a participant is directly related. } \\
\text { Evaluate the centrality of a participant is to identify the position he is in relation to } \\
\text { sharing and network communication. }\end{array}$ \\
\hline Density & $\begin{array}{l}\text { Indicates the percentage of the level of } \mathrm{n} \text { connectivity etwork, being obtained by } \\
\text { dividing the existing relationships with possible links, which may present as low or } \\
\text { high density. }\end{array}$ \\
\hline
\end{tabular}

Note. Source: adapted from Alejandro, V. A. O., \& Norman, A. G. (2005). Manual introdutório à análise de redes sociais: medidas de centralidade. Mexico: Universidad Autonoma Del Estado de México.

According to Spink (1999), analysis per se is understood in light of various categories and contextual information, bringing about the interpretation as an intrinsic element of the research process. Thus, there aren't distinct moments between information gathering and interpretation. Therefore, starting with the definition of the themes that reflect the main research objectives, this mapping led to the delineation of analytical categories, allowing an approximation of the meanings seen as end activities (Spink, 1999).

\section{Analysis and Discussion}

With the creation of interpretative repertoires, we were able to identify the significant learning practices negotiated by the AMFOR entrepreneurs (Table 3), these being related to Continuous Training and Planning of Joint Action projects. Narrowly situated in daily work activities during the development of these two practices, network creation processes emerged from the analysis. These learning practices are described and interpreted below, along with reflections on implications on the development of sustainable practices in the AMFOR small businesses context.

Table 3

Learning Practices Negotiated by the AMFOR Entrepreneurs
1. Continuous Training
2. Planning of Joint Action

Note. Source: empirical research.

\section{Continuous training: life, work and the creation of the AMFOR Network}

As reported by those interviewed, in 2006, the AMFOR Association was sought out by the Brazilian Agency for Support to Small and Medium Enterprises (SEBRAE), through a project called SEBRAE in the Neighborhoods. The program had already attended to some business segments in the José Walter neighborhood where AMFOR is located, but intended to expand its service into the 
furniture sector. Accordingly, there was broad participation of entrepreneurs in the furniture sector in the SEBRAE in the Neighborhoods, considering the possibility of extending the associative links between all participants AMFOR, as well as intensify the actions of capabilities.

Consulting activities of SEBRAE in the Neighborhoods for furniture sector began in 2007. Among the activities carried out falls to the survey of training needs in the areas of business management, credit and furniture design and especially as regards the development of associative capabilities among entrepreneurs in the furniture sector.

As a result AMFOR's entrepreneurs expanded the regular meeting calendar and negotiated the objectives that should be achieved together, having as a goal developing activities related to the SEBRAE in the Neighborhoods project. At these meetings, the group of entrepreneurs intensively discussed the need to develop a training agenda. They highlighted the importance of associative and cooperative work between different organizations in the local furniture sector, among other objectives, and at the same time worked on identifying other existing needs in AMFOR's participating small companies.

As evidenced by Easterby-Smith et al. (2000), groups of people from different organizations and different cultural backgrounds, when meeting for a period and aiming to analyze a problem or develop a project, build situated identities. This, therefore, constitutes a discursive community.

Analysis of documents and participants' speeches revealed that activities of the project Continuous Training, in order to optimize the social impact, delimit the different positions and bring out the meaning of the workplace relationship scenario among AMFOR's entrepreneurs. These positions were mapped from the documents and discursive practices. These show the interaction between the entrepreneurs themselves, the entrepreneurs and consultants, the entrepreneurs and representatives of other supporting organizations (National Service of Industrial Learning [SENAI], SEBRAE, The Furniture Union, Bank of Brazil, local universities and districts associations), the entrepreneurs and their suppliers and, lastly, between the entrepreneurs and their customers.

Table 4 describes the total participants of the AMFOR Network, with its 9 entrepreneurs (RP), 4 Suppliers (FORN), 7 main customers (CLN) 8 Associations (SSA); 3 Consultants (CONS), 01 University (UNIV) and 6 support institutions (INST), totaling 38 participants.

Table 4

Participants AMFOR Network

\begin{tabular}{ll}
\hline Entrepreneurs & RP1, RP2, RP3, RP4, RP5, RP6, RP7, RP8, RP9 \\
\hline Suppliers & FORN1, FORN2, FORN3, FORN4 \\
\hline Customers & CLN1, CLN2, CLN3, CLN4, CLN5, CLN6, CLN7 \\
\hline Consultants & CONS1, CONS2, CONS3 \\
\hline University & UNIV1 \\
\hline Supporting organizations & INST1, INST2, INST3, INST4, INST5, INST6 \\
\hline Districts Associations & ASSOC1, ASSOC2, ASSOC3, ASSOC4, ASSOC5, ASSOC6, ASSOC7, ASSOC8 \\
\hline
\end{tabular}

Note. Source: empirical research.

In Figure 1 below it is possible to visualize the structure of relationships AMFOR Network from connections between participants described above. 


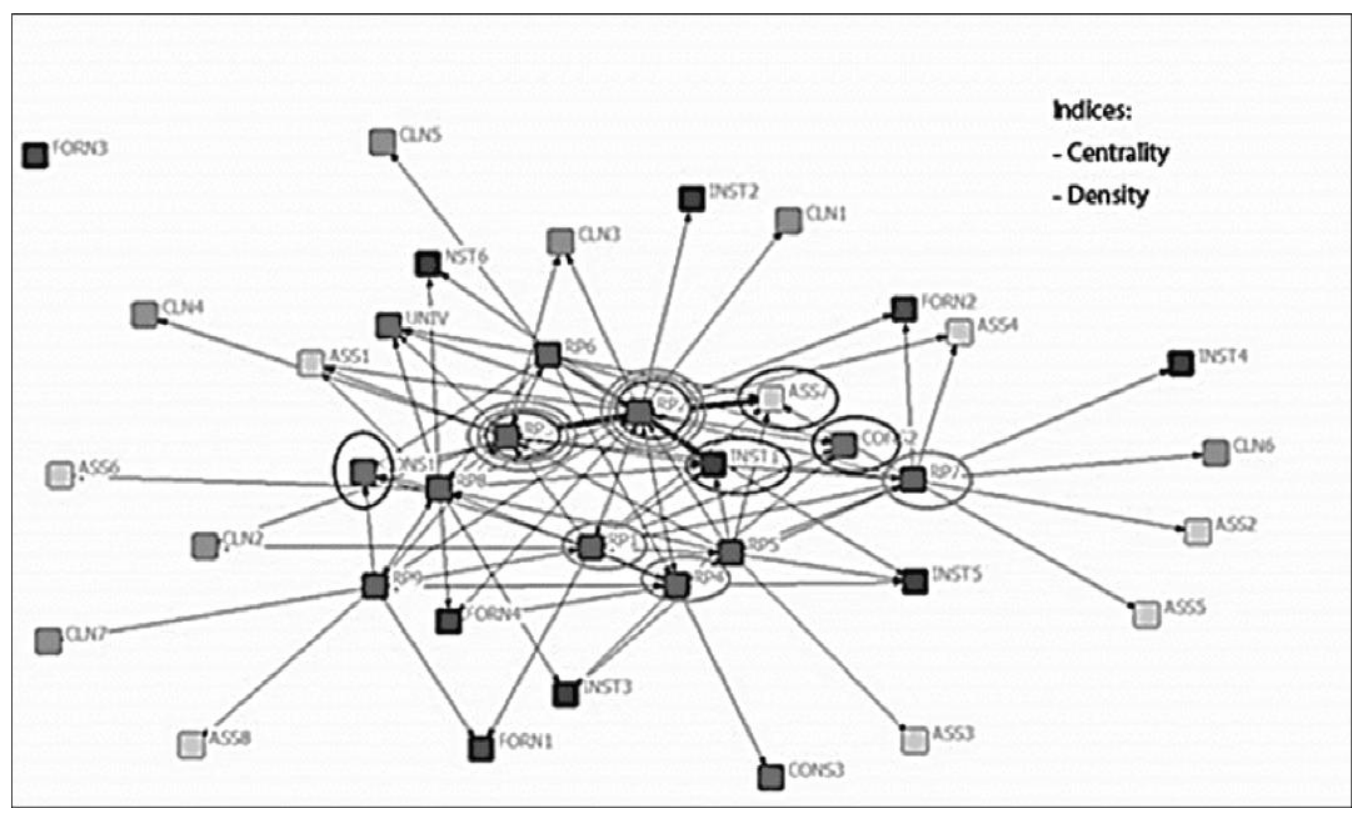

Figure 1. Relationships AMFOR Network Participants.

Source: empirical research, 2013.

The analysis of Figure 1 shows that the level of connectivity of AMFOR network introduced 1406 possible relations and only 198 existing relationships, which points to a low density of possible relationships that could still be explored among participants.

With regard to the placement of actors in AMFOR network, consideration of the indices degree centrality input (indegree-responsiveness) showed that participants P2 $(8,000)$ and RP3 (6000). The high rates of degree centrality output (expansiveness-outdegree) stood out the same participants RP2 $(16,000)$ and RP3 $(13,000)$. These evidences confirm the roles that both participants play by the AMFOR, regarding the foundation of network and leadership in the articulation and coordination of actions / projects of the Network. The Table 5 below present the total indices of centrality of network participants AMFOR.

Table 5

Centrality Conections AMFOR Network

\begin{tabular}{ccc}
\hline \multicolumn{3}{c}{ CONECTIONS NETWORK AMFOR } \\
\cline { 2 - 3 } PARTICIPANTS & CENTRALITY \\
\hline RP1 & OUT & IN \\
RP2 & 10.000 & 4.000 \\
RP3 & 16.000 & 8.000 \\
RP4 & 13.000 & 6.000 \\
RP5 & 10.000 & 5.000 \\
RP6 & 10.000 & 3.000 \\
RP7 & 10.000 & 1.000 \\
& 10.000 & 2.000 \\
\hline
\end{tabular}


Table 5 (continued)

\begin{tabular}{|c|c|c|}
\hline \multicolumn{3}{|c|}{ CONECTIONS NETWORK AMFOR } \\
\hline \multirow[t]{2}{*}{ PARTICIPANTS } & \multicolumn{2}{|c|}{ CENTRALITY } \\
\hline & OUT & IN \\
\hline RP8 & 10.000 & 4.000 \\
\hline RP9 & 9.000 & 2.000 \\
\hline ASS1 & 0.000 & 3.000 \\
\hline ASS2 & 0.000 & 1.000 \\
\hline ASS3 & 0.000 & 1.000 \\
\hline ASS4 & 0.000 & 2.000 \\
\hline ASS5 & 0.000 & 1.000 \\
\hline ASS6 & 0.000 & 1.000 \\
\hline ASS7 & 0.000 & 6.000 \\
\hline ASS8 & 0.000 & 1.000 \\
\hline CLN1 & 0.000 & 1.000 \\
\hline CLN2 & 0.000 & 2.000 \\
\hline CLN3 & 0.000 & 2.000 \\
\hline CLN4 & 0.000 & 1.000 \\
\hline CLN5 & 0.000 & 1.000 \\
\hline CLN6 & 0.000 & 1.000 \\
\hline CLN7 & 0.000 & 1.000 \\
\hline CONS1 & 0.000 & 5.000 \\
\hline CONS2 & 0.000 & 4.000 \\
\hline CONS3 & 0.000 & 1.000 \\
\hline FORN1 & 0.000 & 2.000 \\
\hline FORN2 & 0.000 & 2.000 \\
\hline FORN3 & 0.000 & 0.000 \\
\hline FORN4 & 0.000 & 3.000 \\
\hline INST1 & 0.000 & 7.000 \\
\hline INST2 & 0.000 & 1.000 \\
\hline INST3 & 0.000 & 3.000 \\
\hline INST4 & 0.000 & 1.000 \\
\hline INST5 & 0.000 & 3.000 \\
\hline INST6 & 0.000 & 2.000 \\
\hline UNIV & 0.000 & 4.000 \\
\hline
\end{tabular}

Note. Source: empirical research.

In accordance with the objectives of this research and according to Schatzki (2001) and Reckwitz (2002), participatory dynamics underlying the Continuous Training project can be considered to be a generic primary social unit that enabled social construction. This inference corroborates with Spink's methodological principle (1999) that interpretative repertoires incorporate subjects' positions in interactions, and these are placed in a constant negotiation process delineating an area of interpersonal, community discourse, according to Easterby-Smith et al. (2000).

It was also evident from document analysis that the entrepreneurs' participation in these activities perpetuated to evolve over the years 2007, 2008 and 2009, constituting collectively-situated discursive identities, enabling accomplishment of the remaining less-instrumental and less-intentional objectives that permeated organizational activities. This continued interaction allowed for practice reflexivity among the entrepreneurs, therefore representing a precondition for learning to occur. It is inferred that this set of activities and interactions (knowing) came prior to the knowledge related to 
institutionalizing a new vision of business network (Easterby-Smith et al., 2000; Gherardi, 2008 Gherardi \& Nicolini, 2001):

\begin{abstract}
"we perceived that there was a paradigm break, people ceased to be individual islands of work to be one, that was when the penny dropped for each of us to be a network, it was noticed that in this form moving forward we could work together, open the secrets of other factories to each other and thus begin to grow.... So when the agent understood the association scenario, the agent is understood as an entrepreneur, and from there we were promptly identifying our difficulties and grouping.... The events led to a questioning of the postures related to interpersonal relationships, and that the associations were very important tools that made the network focus and change internally and adapt to market needs" (Documentary analysis; Entrepreneurs RP1 and RP3).
\end{abstract}

These discursive passages reveal, according to Hardt (1996), Schatzki (2001), Easterby-Smith et al. (2000) and Whittington (2006), that the denial of dichotomies of who is in and who is out allow displacement and boundary crossing between small companies and between other involved organizations, paving the way to socially shape and create the AMFOR Network, per se.

The Continuous Training project sparked reevaluation activities and strengthened old and new work practices. This learning process guaranteed an analysis of these practices, the development and redevelopment of new and useful propositions to reorganize working practices; going beyond work skills development, to combine knowing how to act (behavior) and knowing how to do (know-how) as learning methods during quotidian work (Antonacopoulou et al., 2005). According to Gherardi (2006), work practices are recognized as a means of assessment, and although they are heavily altered from the context in which are shown, they are still recognizable. As disclosed by one of the interviewees, members of AMFOR reflected on their daily work practices and continuously reformulated them and unified learning and organizing (learning-in-organizing) in the small business AMFOR Network (Gherardi, 2009), as shown in the following discursive block:

\footnotetext{
"We were analyzing our work practices to see if what we were doing was right and we began to question the processes where an agent could implement improvements in management and production organization.... Growth was when we realized that even working with custom-made furniture where you work in a universe of many variables to coordinate the outcome, which is furniture, we noticed that the furniture was always made of sheets, so we will only change some measures and some facades. Therefore, we standardized the way to manufacture furniture, but these variables in furniture revolve around $30-40 \%$. Moreover, we managed to advance because we standardized the process right now" (Entrepreneur RP3).
}

During participation in the Continuous Training project, learning as a way of life (Antonacopoulou et al., 2005) was characterized by exploration, questioning and re-framing processes, with the flow of new discursive identifications situated among participants, enabling the construction of new, sustainable learning-practices reflected in corporate sustainability of the companies.

In this sense, new practices were incorporated into the actions implemented in the participating companies of the network, such as the: (a) reduction of energy waste on the production line, (b) implementation of a plan for cutting the sheets and wood, allowing the reduction of losses material, (c) acquisition of new labor equipment safety, (d) realization of collective purchasing.

This evidence may be confronted with the theoretical placements of Barbieri, Vasconcelos, Andreassi, and Vasconcelos (2010) when they say that the adherence of social mobilization comes against a need to replace old practices by others that interpret the principles, goals and directions of recent movement. According to one of the entrepreneurs, there were many transformations, the most significant of which was perhaps "our self-visualization as entrepreneurs, that until then did not exist, which allowed us to conquer ... a promising and sustainable business" (Entrepreneur RP2).

"we began to think about making a plan over time .... Then came the theme 'industrial cabinet maker, a
new challenge' which was what we envisioned, the cabinet maker [industrial] would have a mindset to
develop sustainably.... Today an agent has a 'new' cabinet maker format in our head, not as a cabinet 
maker; because the status of our association changed today, we are the custom-made furniture manufacturers association of the State of Ceará. Because we already have in mind what it will be in the future and now it is just a question of more financing to implement what is planned" (Entrepreneur RP2).

"know when you visualize which path and you have to build this path to get there; what is missing is the time to get to this point at this moment, but we see the way to go there" (Entrepreneur RP4).

Different narrative lines that were previously articulated may be related to those put forth by Barbieri (2007) when the emphasis on the discussion of sustainability seems to be the motivation for excellence and corporate social mobilization that has been practiced by different segments of a business. Beyond a cause that defends adherence to sustainability from the outside to inside, more recently, companies began to join such a project influenced by factors related to their own business needs - being a member of this movement has become a competitive factor, a differentiating factor for companies to remain in the market.

\section{Planning of joint actions: life, work and sustainability in AMFOR}

The second set of discursive practices evidenced in AMFOR was the Planning of Joint Actions, which began in 2007 and was associated with Continuous Training practices and the creation of a Network per se, it is also proposed in this study as an assessing measurement of a primary generic social unit (Gherardi, 2006; Reckwitz, 2002; Schatzki, 2001). The section below describes how the social unit was formed and expanded from the interactive dynamics underlying Planning of Joint Action. Moreover, it shows participants' positions, allowing movement between the borders of the different perspectives and organizations involved, and promoting learning how to negotiate current relationships and how to negotiate changes in these relationships (Easterby-Smith et al., 2000):

\footnotetext{
"AMFOR is a network formatted into six sectors, it has a marketing sector, a quality sector, an events sector and an institutional actions sector, which is mine, I go after the institutional partners .... Therefore, each sector is responsible for each action set, and then the documents are prepared and executed jointly as planned actions. I, for example, was responsible for implementing the idea of the local furniture center; I am moving this process along with the rest of the entrepreneurs and representatives of other local institutions. We met and talked a lot about how to make it work.... We are interacting and scheduling meetings with technicians from all organizational and governmental areas in order to accomplish this project" (Entrepreneur RP2).
}

According to institutional documents, beginning from the interaction with other support organizations participating in the AMFOR Network (SENAI, SEBRAE, The Furniture Union, Bank of Brazil, local universities and districts associations), a need emerged for activity related to participation in national and international fairs. With the completion of this activity, interactions and conversations between the entrepreneurs and their new peers in other regions allowed for the negotiation of new contracts, the acquisition of new equipment, as well as resolving problems through circulation and sharing of tacit knowledge that had already been developed in other work places, in the words of an entrepreneur:

\footnotetext{
"The exchange of information between entrepreneurs during fairs serves as a kind of consultancy and you discover that you gain a lot. If you have a bottleneck, you know an entrepreneur and soon you are already talking about this problem. He has already been through this experience, and then these tips are like gold. We do not stop talking during the days of the fair. Therefore, we have tips that are not in books, but from each person's experience" (Entrepreneur RP2).
}

When asked about implementing these new practices, one of the respondents reported that the transformation in the business' attitude related to the processes of manufacturing and production design, in adaptation and acquisition of new technologies and in obtaining knowledge from suppliers and technicians, were derived from activities related to participation in fairs. This learning promoted during participation in fairs is consistent with the proposition of the central idea in practice, the fact 
that knowledge is created from something practical (knowing) and not a result of decontextualized abstractions (Gherardi, 2008):

"The change of stance is visible after participation in fairs ... For example, FEMAC showed that a company made a piece of furniture every 30 minutes, so it is a process, a way to make and organize production and we can do it.... it is a new technology that we know and will take hold, and today the AMFOR companies are moving on from old cabinetmaking technology and industrializing at an increasingly higher rate and thus opening new markets" (Entrepreneur RP3).

Continuous Training associated with Planning of Joint Actions practices and the creation of its Network per se will take place in a form that stimulates new learning practices that favor Participation in Fairs. These new practices expanded the discursive community space with networking circularity of new knowledge and practices between the entrepreneurs, suppliers and customers of other organizations and regions. These analyses corroborate Gherardi's (2006) proposition of representing practices through a web of connections in action, connectivity, and linking these actions while they continuously multiply and propagate, fostering learning and meaning new worklife perspectives.

The modalities of an entrepreneur's actions in everyday life at work involve different methods of space-time organization of subjects' actions, which can be interpellated from the unfolding of these actions in the daily organization of small businesses (Schatzki, 2006). Correspondingly, AMFOR network entrepreneurs tried to reflect their lifestyle practices at work, seeking to develop sustainable learning practices in small businesses.

Some discursive clips related to Planning of Joint Actions activities pointed to this circularity of knowledge derived from the expansion of the social composition of AMFOR's Network, involving negotiations that dealt as much with socio-environmental management, as with markets and regional socio-economic development.

Focusing on the relational modalities in daily work that unfold and articulate with management practices, Schatzki's (2006) analysis conflicts with Ribeiro's (2001) assertions. Schatzki (2006) contends that corporate practices are sustainable when they are capable of creating long-term value for shareholders, and can only then contribute to the solution of local social, economic and environmental problems.

"Recently on the environmental area, we are talking about the use of reforested wood and the importance of reusing pieces of wood (MDF) for production of doors and drawers, as well as the sale of sawdust to ceramic factories" (Entrepreneur RP2).

"We are reviewing marketing concepts, preparing for the implementation of improvements to vending locations (show room) installed by several resellers in the Ceará market who became more aggressive and anxious to meet customer expectations" (Entrepreneur RP2).

\footnotetext{
"We are very concerned about our employees, among the initiatives is updating personal protective equipment - PPE. The furniture segment is increasingly contemplating these practices in relation to people. New habits and practices were incorporated with the establishment of the network, such as a plan to reduce materials and energy waste during the production process and management" (Entrepreneurs RP3 and RP5).

"In addition to concerns with the market, environment and people, we are also contacting professors from local universities to do joint work ... we launched, for example, a competition within a particular topic of interest in the furniture sector to reward the best project for AMFOR to execute, thus enabling the creation of a local design.... Therefore, eventually creating for everyone an industry with the face of Ceará, with the support of the university, government and business" (Entrepreneur RP2).

"The repercussions of all this in terms of local job generation is very great; look, if the agent considers that smaller companies had at least three employees, today smaller companies have 10 employees, therefore the gain is more than $300 \%$, but this number is higher, I'm being modest. The network has companies that have 25 employees. I am putting an average of 10" (Entrepreneur RP2).
} 
These different practices - (a) the use of reforested wood; (b) the reuse of pieces of wood; (c) marketing management and expansion of points of sales (showroom); (d) improvement of human resource practices related to worker safety; (e) improving the design; (f) generation of local labor highlighted are consistent with the statement Schatzki (2002) to emphasize that the social site is composed of an interwoven mesh of different practices and arrangements that are interconnected and are articulated through different human activities. This network is the locus where social entities act, relate, unfold, are positioned in relation to each other, making meanings and identities (Schatzki, 2002).

The previously articulated discursive blocks reaffirm a comprehension of the organizations' knowledge as social worlds and reveal the link between learning in organizing while participating in a practice, resulting in the transformation of knowledge, labor production and reproduction, social activities and new perspectives of life (Antonacopoulou et al., 2005; Elkjaer, 2001; Gherardi, 2008).

\section{Final Thoughts}

According to the discursive community analysis formed by AMFOR entrepreneurs, the underlying activities and processes of the Continuous Training projects associated with those from Planning of Joint Actions emerged as primary social units that allowed social activities within learning practices to flourish. These activities, when carried out in an established form, stimulated new practices through a communication web in action that multiplied and continually propagated, growing this discursive space among other support organizations and ultimately resulting in the creation of the AMFOR Network per se.

It became evident that although this has in part been institutionalized learning in formal educational contexts and put forth by external agents (SEBRAE), it was put into action and use by participating entrepreneurs from a complex organizational context, and above all, through the logic which prevailed there.

Accordingly, the analysis presented here sought to articulate an understanding of knowledge and knowing processes and activities as a non-univocal space of work, practices and life. This revealed the reflexive character that outlined positions and negotiations that demarcated subjects' action, crossing into the normative sphere of management processes. These interstices and boundaries are where AMFOR Network organizational creation processes occurred per se.

The underlying logic of these processes was not related to knowledge as an autonomous body of propositions, but rather permeated with new identities and modes of action that were constituted along the way. This outlined new world images and different life perspectives that played out in everyday work, providing learning opportunities in the Small Businesses Network under study.

In this sense, underlying learning practices were evidenced in the following action set: the actions related to implementation of the Continuous Training project that triggered actions regarding the creation of the AMFOR Network per se. In addition, Planning of Joint Actions practices that led to an important set of actions relating to Participation in Fairs.

The interweaving of these practices - this play between knowing and skills - enabled the individual entrepreneurs to emerge as negotiators of their positions in the AMFOR Network per se, articulating a subjective stance in the face of objective discussions about sustainable management performance in companies. This evidence was found in the replacement of old practices by others based on new goals and directions, among them: long-term planning of the wood-working industry; use of reforested wood; reuse of scrap wood; the sale of sawdust; energy and waste reduction plans, the implementing of the local furniture center and generation of local jobs. Developing this competence to act suggested that organizations are social worlds, forming a pattern that holds together life, work and organizational practices. 
It also shows that the narrative blocks articulated in this research highlight the evolving practices in constant evolution (knowing), based on the link between learning and organizing, between knowing and doing (learning-in-organizing). This provided for learning while participating in a discursive community and illuminated an important theoretical contribution to be developed in future studies related to the question of circularity and transformation of knowledge in the organizing practices that are translated between network actors.

These articulations showed the relevance of this research, by demonstrating a void in the literature with little exploration related to understanding joint actions that are negotiated, circulated, transformed and reproduced in an actors' network, while learning sustainable life and work practices.

The research findings may guide development of learning practices underlying management issues, such as guiding the formulation of public policies in order to provide conditions for the sustainability of small company networks.

Accordingly, some questions for future studies in other contexts including how social labor can be based on an interdisciplinary perspective of management. How do the dimensions concerning learning, working and living associate and integrate? How does the movement and translation of knowledge in learning processes and organization of actor networks occur?

\section{References}

Alejandro, V. A. O., \& Norman, A. G. (2005). Manual introdutório à análise de redes sociais: medidas de centralidade. Mexico: Universidad Autonoma Del Estado de México.

Antonacopoulou, E. (2008). On the practice of practice: in-tensions and ex-tensions in the ongoing reconfiguration of practices. In D. Barry \& H. Hansen (Eds.), The sage handbook of new approaches in management and organization (pp. 112-131). Los Angeles: Sage.

Antonacopoulou, E., Jarvis, P., Andersen, V., Elkjaer, B., \& Hoyrup, S. (Eds.) (2005). Learning, working and living. Mapping the terrain of working, life, learning. New York: Palgrave Macmillan.

Barbieri, J. C. (2007). Gestão ambiental empresarial: conceitos, modelos e instrumentos. São Paulo: Saraiva.

Barbieri, J. C., Vasconcelos, I. F. G. de, Andreassi, T. \& Vasconcelos, F. C. de (2010). Inovação e sustentabilidade: novos modelos e proposições. Revista de Administração de Empresas, 50(2), 146-154. doi: 10.1590/S0034-75902010000200002

Bauer, M. W., \& Gaskell, G. (2002). Pesquisa qualitativa com texto, imagem e som. Um manual prático. Petrópolis, RJ: Vozes.

Brown, J. S., \& Duguid, P. (1991). Organizational learning and communities-of-practice: toward a unified view of working, learning, and innovation. Organization Science, 2(1), 40-57. doi: 10.1287/orsc.2.1.40

Cook, S. D. N., \& Yanow, D. (1993). Culture and organizational learning. Journal of Management Inquiry, 2(4), 373-390. doi: 10.1177/105649269324010

Easterby-Smith, M., Crossan, M., \& Nicolini, D. (2000). Organizational learning: debates past, present and future. Journal of Management Studies, 37(6), 783-796. doi: 10.1111/1467-6486.00203 
Elkjaer, B. (2001). Em busca de uma teoria da aprendizagem social. In M. Easterby-Smith, J. Burgoyne, \& L. Araujo (Coords.), Aprendizagem organizacional e organizações de aprendizagem. Desenvolvimento na teoria e na prática (pp. 100-118). São Paulo: Atlas.

Elkjaer, B., \& Wahlgren, B. (2005). Organizational learning and workplace learning - similarities and differences. In E. P. Antonacopoulou, P. Jarvis, V. Andersen, B. Elkjaer, \& S. Hoyrup (Eds.), Learning, working and living. Mapping the terrain of working, life, learning (pp. 15-32). New York: Palgrave Macmillan.

Gergen, K. (1985). The social constructionist movement in modern Psychology. American Psychologist, 40(3), 266-275. doi: 10.1037/0003-066X40.3.266

Gherardi, S. (2000). Where learning is: metaphors and situated learning in a planning group. Human Relations, 53(8), 1057-1080. doi: 10.1177/0018726700538002

Gherardi, S. (2001). From organizational learning to practice-based knowing. Human Relations, 54(1), 131-139. doi: 10.1177/0018726701541016

Gherardi, S. (2006). Organizational knowledge: the texture of workplace learning. London: Blackwell.

Gherardi, S. (2008). Situated knowledge and situated action: what do practice-based studies promise? In D. Barry \& H. Hansen (Eds.), New approaches in management and organization (pp. 516525). London: Sage.

Gherardi, S. (2009). Introduction: the critical power of the 'practice lens'. Management learning, 40(2), 115-128. doi: 10.1177/1350507608101225

Gherardi, S., \& Nicolini, D. (2001). The sociological foundations of organizational learning. In M. Dierkes, A. Berthoin Antal, J. Child, \& I. Nonaka (Orgs.), The handbook of organizational learning and knowledge (pp. 35-60). Oxford: Oxford University Press.

Hardt, M. (1996). Gilles Deleuze: um aprendizado de filosofia. São Paulo: Editora 34.

Lave, J., \& Wenger, E. (1991). Situated learning: legitimate peripheral participation. New York: Cambridge University Press.

Nicolini, D., Gherardi, S., \& Yanow, D. (2003). Knowing in organizations: a practice- based approach. Armonk, NY: M. E. Sharpe.

Nicolini, D., \& Meznar, M. B. (1995). The social construction of organizational learning: conceptual and practical issues in the field. Human Relations, 48(7), 727-746. doi: $10.1177 / 001872679504800701$

Reckwitz, A. (2002). Toward a theory of social practices: a development in culturalist theorizing. European Journal of Social Theory, 5(2), 243-263. doi: 10.1177/13684310222225432

Ribeiro, W. C. (2001). A ordem ambiental internacional. São Paulo: Contexto.

Schatzki, T. R. (2001). Introduction: practice theory. In T. R. Scahtzki, K. K. Cetina, \& E. V. Savigny (Eds.), The practice turn in contemporary theory (pp. 1-14). Routledge: London.

Schatzki, T. R. (2002). The site of the social: a philosophical account of the constitution of social life and change. University Park: Pennsylvania State University Press.

Schatzki, T. R. (2006). On organizations as they happen. Organization Studies, 27(12), 1863-1873. doi: 10.1177/0170840606071942 
Spink, M. J. (1999). Práticas discursivas e produção de sentidos no cotidiano. Aproximações teóricas e metodológicas. São Paulo: Cortez.

Vinha, V. da (2003). As empresas e o desenvolvimento sustentável: da eco-eficiência à responsabilidade social corporativa. In P. H. May \& M. C. Lustosa (Orgs.), Economia do meio ambiente: teoria e prática (pp. 173-195). Rio de Janeiro: Campus.

Warde, A. (2005). Consumption and theories of practice. Journal of Consumer Culture, 5(2), 131-153. doi: $10.1177 / 1469540505053090$

Whittington, R. (2006). Completing the practice turn in strategy research. Organization Studies, 27(5), 613-634. doi: 10.1177/0170840606064101 